\title{
SAUDADES DA FE-USP
}

\author{
Jorge Ramos do Ó \\ Instituto de Educação, Universidade de Lisboa, Portugal \\ jorge.o@ie.ul.pt
}

\begin{abstract}
RESUMO
Este artigo centra-se no problema da socialização académica. É o testemunho direto e pessoal da experiência que o seu signatário, proveniente da Universidade de Lisboa, tem tido nos últimos 20 anos, como professor convidado e conferencista na Faculdade de Educação da Universidade de São Paulo. Trata-se de exprimir gesto de gratidão face a uma hospitalidade e um acolhimento generosos, mas, também, de ensaiar um exercício de recuperação da memória no qual se reflete acerca da imagem mais remota que temos da própria universidade, isto é, a de uma comunidade caracterizada pela partilha e pela reciprocidade na construção do pensamento e da escrita. Vê na pedagogia do seminário a espiral aventurosa em que o estar-aser-junto académico se liga intrinsecamente à construção de um pensamento inventivo. Procura assim dar uma contribuição para a discussão, sempre por concluir, acerca da pedagogia da criação científica.
\end{abstract}

Palavras-chave: Faculdade de Educação da Universidade de São Paulo. Comunidade académica. Pedagogia do Seminário. Escrita académica.

\section{RECUERDOS DE LA FE-USP!}

\section{RESUMEN}

Este artículo se centra en el problema de la socialización académica. Es el testimonio directo y personal de la experiencia que su firmante, procedente de la Universidad de Lisboa, ha tenido en los últimos 20 años como profesor invitado y conferenciante en la Facultad de Educación de la Universidad de São Paulo. Se trata de expresar un gesto de gratitud hacia una generosa hospitalidad y acogida, pero también de ensayar un ejercicio de recuperación de la memoria en el que se reflexiona sobre la imagen más remota que tenemos de la propia universidad, es decir, la de una comunidad caracterizada por el compartir y la reciprocidad en la construcción del pensamiento y la escritura. Ve en la pedagogía del seminario la espiral aventurera en la que el estar juntos académico está intrínsecamente ligado a la construcción del pensamiento inventivo. Pretende así hacer una aportación al debate, siempre inacabado, sobre la pedagogía de la creación científica.

Palabras clave: Facultad de Educación, Universidad de São Paulo. Comunidad académica. Pedagogía de los seminarios. Escritura académica.

\section{MISS FE-USP!}

\begin{abstract}
This article focuses on the problem of academic socialisation. It is the direct and personal testimony of the experience that its signatory, coming from the University of Lisbon, has had in the last 20 years as a guest professor and lecturer at the Faculty of Education of the University of São Paulo. It is about expressing a gesture of gratitude towards a generous hospitality and
\end{abstract}


welcome, but also about rehearsing an exercise of memory recovery in which one reflects on the most remote image we have of the university itself, that is, that of a community characterised by sharing and reciprocity in the construction of thought and writing. the article aims at identifying seminar pedagogy as the expression of an adventurous spiral in which the academic "coming-to-be-together" is intrinsically connected to the creation of inventive thinking processes. It seeks to contribute to what is an always-unfinished discussion about pedagogy and scientific creation.

Keywords: Faculty of Education, University of São Paulo. Academic Community. Seminar Pedagogy. Academic writing

\section{SOUVENIRS DE FE-USP!}

\section{RÉSUMÉ}

Cet article se concentre sur le problème de la socialisation académique. Il s'agit du témoignage direct et personnel de l'expérience que son signataire, issu de l'Université de Lisbonne, a vécue au cours des 20 dernières années en tant que professeur invité et chargé de cours à la Faculté d'éducation de l'Université de São Paulo. Il s'agit d'exprimer un geste de gratitude envers une hospitalité et un accueil généreux, mais aussi de répéter un exercice de récupération de la mémoire dans lequel on réfléchit à l'image la plus lointaine que nous avons de l'université ellemême, c'est-à-dire celle d'une communauté caractérisée par le partage et la réciprocité dans la construction de la pensée et de l'écriture. Elle voit dans la pédagogie du séminaire la spirale aventureuse dans laquelle l'être-ensemble académique est intrinsèquement lié à la construction d'une pensée inventive. Il cherche ainsi à apporter une contribution à la discussion, toujours inachevée, sur la pédagogie de la création scientifique.

Mots-clés: Faculté d'éducation, Université de São Paulo. Communauté académique. Pédagogie du séminaire. Écriture académique.

\section{INTRODUÇÃO}

Imagino a Faculdade de Educação da Universidade de São Paulo como a minha morada - aquela à qual desejo sempre regressar -, desde que, em Fevereiro de 1998, tive a oportunidade de apresentar ao II Congresso Luso-Brasileiro de História da Educação uma comunicação sobre uma parcela de minha tese de doutoramento, que nessa altura estava a preparar. Foi um início de um belo encontro, de todos o mais exaltante que tive fora de Portugal, em absoluto fundamental para pensar os sentidos possíveis das minhas atividades de ensino e investigação. Começo por dizer que a generosidade de colegas e alunos, assim como as consequentes parcerias, cumplicidades e relações de amizade que desde então pude estabelecer, me devolveram o que há de melhor no mundo académico - a certeza de que estamos no interior de uma comunidade, real e imaginária, de diálogo e reflexão comum. O pensar-junto, o estar em relação-com, um ermergir-ir-reflexivo são as melhores recordações que guardo das mais de duas décadas entretanto transcorridas. 
$\mathrm{Na}$ realidade, pude experimentar formas reais de interação que me afastaram da solidão pedagógica que se abate há tantos séculos sobre docentes e alunos, impedindo-os tantas vezes de entrar em verdadeira relação. Qualquer investigador-professor sabe que precisa de multiplicar afetos e procurar a companhia de outros para que a sua potência de pensar e agir se desenvolva. Aí reside o coração da universidade. E também eu fui então levado a perceber que qualquer problema de investigação é atravessado e se deve apresentar como uma imagem do avanço do pensamento no interior de uma sociedade de amigos. Em tudo quanto pude escrever de lá para cá, conjeturei sempre que os meus interlocutores, leitores e destinatários tinham os rostos de colegas e alunos que conheci e com quem trabalhei na FE-USP. Nunca conseguirei expressar devidamente a minha dívida de gratidão por essa presença assídua, por essa fantasia que transporto da reciprocidade partilhada, de um viver-junto para se criar-a-si-próprio.

$\mathrm{Na}$ viragem do milénio tive a oportunidade de começar a trabalhar em Educação Comparada, no âmbito do Projeto europeu PRESTIGE - coordenado por António Nóvoa, que então orientava o meu doutoramento, e por Jürgen Schriewer -, mas cujos braços viriam a estender-se à Faculdade de Educação da Universidade de São Paulo. Fui ainda membro da equipa de investigadores do Programa CAPES/ICCTI denominado Estudos sobre a Escola: Brasil e Portugal séculos XIX e XX, com a direção de António Nóvoa e Denice Catani. A partir daí comecei a conhecer de perto os trabalhos de outros historiadores da Educação da FE-USP, casos de Cynthia Pereira de Sousa, Carlota Boto, Nelson Schapochnik e Jaime Cordeiro. Denice Catani teve a generosidade de me convidar, ainda em Setembro de 2000, para fazer duas palestras sobre o Movimento da Educação Nova e os problemas teóricos da minha tese de doutoramento que viria a terminar dois anos depois.

Com esta monografia, a que dei o título O governo de si mesmo: Modernidade pedagógica e encenações disciplinares do aluno liceal (último quartel do século XIX-meados do século $X X)$, o meu objetivo era então o de tentar compreender que tipo de ator social se intentou produzir em Portugal sob a influência do discurso psicopedagógico moderno ocidental (Ó, 2003). Nela tratava da produção histórica de um determinado tipo de ser; e pude defender que os estudos secundários foram conquistando a sua autonomia porque exatamente procuraram pensar, agir e intervir sobre as atitudes, disposições e comportamentos dos alunos. Assim fui levado a perceber que a matéria ética é historicamente indissociável do postulado segundo o qual a escola vem fabricando um tipo de ator que deve, ele mesmo, transformar-se no sujeito da sua própria educação. A ética não se nos apresenta aí como um assunto de pregação mas, ao contrário, enquanto problema existencial, associado ao isolamento essencial do escolar. Nesse texto, e em referência àquele longo arco temporal, determinei-me em compreender a 


\section{$(\mathrm{cc}) \mathrm{EY}$}

socialização escolar num quadro de ação - e não de inculcação -, por intermédio do qual se começou a admitir que as crianças e jovens só poderiam entrar num efetivo processo de aprendizagem quando tivessem a capacidade de dominar internamente as várias experiências escolares em que se viam envolvidas. Tratava-se, no essencial, de dar conta de uma apropriação integradora assente numa multiplicidade de jogos estratégicos e de situações relacionais em que cada membro da população escolar tem sido convidado, ao longo da época contemporânea, a constituir-se a si mesmo como indivíduo autónomo, racional e, uma vez já fora da escola, capaz de dar o seu contributo particular para a integração moral de todo o tecido social, para a paz social. A meu ver, a educação secundária veio a estruturar-se na longa duração como um trabalho disciplinar sobre o eu. Na minha tese ecoava a máxima disciplinar tão bem explicitada por Nietzsche, a máxima do Torna-te no que deves ser!

No seu acontecer, esta investigação colocou-me sobretudo reptos de natureza teórica. Desde logo, relacionados com o conceito de subjetividade, que procurei tratar como o resultado quer das interações face a face, quer da capacidade de monitorização do pensamento e da autorregulação do comportamento individual. Era, estava então em crer, esta dimensão relacional e reflexiva que vinha produzindo na nossa cultura o aluno como ator social. E assim, visando a especificidade dos percursos individuais e as sensibilidades de cada um deles, a escola surgia-me como uma verdadeira instituição da subjetivação política, ou seja, uma organização capaz de mobilizar sistematicamente todos os seus recursos técnicos e práticas para a formatação das aspirações, necessidades e desejos do aluno. A tese da tese era a de que o também chamado ensino médio viu na conduta o seu problema pedagógico maior e na cultura de si a ocupação mais importante.

Para a constituição da minha agenda de investigação nessa época, acerca do que deveriam ser a formação e os papéis do aluno, foi determinante a leitura dos trabalhos teóricos, e também das análises empíricas, produzidos por Michel Foucault no contexto da redação e publicação dos três volumes da História da sexualidade. Foucault foi aí definindo um território de análise que cruza permanentemente os domínios da ética com os da política. O termo governamentalidade e a expressão tecnologias do eu, remetendo um para o outro e esclarecendo-se mutuamente, eram os que melhor definem a inflexão operada nos seus últimos projetos de investigação, visando compreender as bases sobre as quais as modernas práticas da subjetivação têm vindo a ser construídas na modernidade. $\mathrm{O}$ objetivo das duas tópicas era o de gerar toda uma aparelhagem conceptual que pudesse tornar explícita tanto uma visão micro do tecido social, tomando o indivíduo no seu próprio universo, quanto uma visão macro, revelando uma preocupação de governo da população no seu conjunto. Como se as dinâmicas da 
individualização e da totalização correspondessem a um e a um só processo - e nós devêssemos falar de identidade como um problema essencialmente relacional -, os últimos textos de Foucault mobilizaram-se para inventariar os mecanismos de poder desenvolvidos, a partir do século XVI e na Europa Ocidental, no sentido de administrar e supervisionar as condições de vida dos cidadãos, de todos e de cada um em particular. Os seus escritos finais procuraram desvendar a emergência de todo um novo exercício do poder soberano ligado à razão de Estado.

A governamentalidade corresponderia, no seu entendimento, ao desencadear de toda uma arte caracterizada pela heterogeneidade de autoridades e agências, empregando para tanto uma desmesurada variedade de técnicas e formas de conhecimento científico destinadas a avaliar e a melhorar a riqueza, a saúde, a educação, os costumes e os hábitos da população. De acordo com Foucault, este modelo biopolítico terá conhecido uma enorme aceleração a partir do século XVIII. Com efeito, o Estado moderno foi-se afirmando através de formas de notação, coleção, representação, acumulação, quantificação, sistematização e transporte de informação, alimentando-se ainda do propósito de reinventar permanentemente novas modalidades de divisão do espaço e do tempo social. Estas operações de poder-saber terão configurado num dispositivo ágil para o governo da nação no seu conjunto e disponibilizaram igualmente critérios para o aperfeiçoamento ético.

Quando falava em tecnologias do eu, Foucault referia-se a todo este conjunto de técnicas performativas de poder que incitaram o sujeito a agir e a operar modificações sobre a sua alma e corpo, pensamento e conduta, vinculando-o a uma atividade de constante vigilância e adequação aos princípios morais em circulação na sua época. A subjetivação, tal como no-la apresentou o autor de Vigiar e punir, envolve portanto exercícios de inibição do eu, ligados às dinâmicas políticas de governo e ao desenvolvimento de formas de conhecimento científico. A sociedade moderna ter-se-á por essa via transformado numa sociedade essencialmente disciplinar. Foi esta preocupação geral que, de facto, animou a investigação foucaultiana dos últimos anos: analisar a formação do homem moderno através dos mecanismos por intermédio dos quais cada um se deve passar a relacionar consigo mesmo e a desenvolver toda uma autêntica arte de existência destinada a reconhecer-se a si como um determinado tipo de sujeito. E um sujeito cuja verdade pode e deve ser conhecida. A ética torna-se unicamente inteligível como um domínio da prática.

Persuadi-me então que este posicionamento intelectual trazia agregado um arsenal de ferramentas que me iria ajudar a compreender as racionalidades, as técnicas e as práticas que historicamente envolvem o cálculo e a formatação das capacidades humanas. Parecia-me que o modelo de aluno autónomo que a escola tem vindo de há muito a promover, e sob tradições 
$(\mathrm{cc}) \mathrm{EY}$

político-culturais as mais diversas, entronca por inteiro nesta tecnologia de governo e podia ser por ela melhor problematizado. A virtualidade explicativa dos fenómenos sociais proposta por Foucault entusiasmava-me então bastante e criava, para mim, a possibilidade, de abrir uma espécie de varanda sobre o mundo num espaço-tempo dilatado, que normalmente os historiadores recusam, optando antes por conjunturas mais estreitas e circunscritas. Estava naquela altura determinado em escrever - e a verdade é que ainda hoje permaneço afiliado a essa possibilidade - o que ele mesmo designara em Vigiar e punir como sendo uma história do presente. A minha ideia de partida era pois a de conseguir traçar uma narrativa das nossas convicções atuais em matéria de educação secundária. De onde vêm as ideias, as formações sociais e institucionais que aceitamos como naturais na atualidade. $\mathrm{O}$ conceito de genealogia, desenvolvido por Foucault a partir de Nietzsche, enquadrava-se no programa nominalista que então perseguia. É que para o genealogista não há essências fixas, leis incontornáveis ou finalidades metafísicas; o seu objetivo não é ir às origens, mas antes tentar intersectar a proveniência e a linhagem de um problema ou de uma coisa; na assunção de que os factos não falam por si mesmos, tende a colocar a ênfase num tipo de sistematização e conceptualização que assume continuidade interativa entre a elaboração das teorias e das hipóteses; em termos de trabalho empírico dá uma importância central às relações de poder, aos processos de mudança. Tratava-se, numa palavra, de tentar traçar uma narrativa histórica a partir de um plano e em direção a um objetivo que pudesse desinstalar o leitor relativamente às suas próprias convicções internas acerca dos sistemas de educação e ensino, assim como do modo como fomos produzindo a categoria social de aluno. A genealogia pretende mostrar que os nossos objetos foram sendo historicamente construídos, peça por peça, compactando tradições muito diferentes e que não imaginamos de modo algum estarem associadas e ainda menos fundidas. São pois narrativas muito específicas, particulares, algumas delas mesmo descontínuas, todavia com implicações gerais. Nietzsche procurou mostrar que não há um sentido - uma razão -, mas todo um lado fluido, uma síntese global de sentidos, de fins e utilizações civilizacionais para cada conceito moral cujo conteúdo tomamos como inquestionável. Como ele mesmo também gostava de afirmar: definível é apenas aquilo que não tem história.

Ora, foi na FE-USP que pude começar a falar aberta e regularmente desta minha investigação nos termos que acabo de explicitar e a sentir uma cumplicidade com as minhas hipóteses de trabalho, através de colegas brasileiros cuja trajetória intelectual se encontrava de resto muito mais sedimentada e consolidada que a minha. Um privilégio, portanto. Recebi o primeiro convite para ali ser professor visitante, através de Denice Catani - com quem mantenho desde aí grande interlocução e uma estreita relação de amizade - entre Novembro e 
(cc) EY

Dezembro de 2003. E a esse seguiram-se mais quatro, sendo que a estadia de 2011 foi a mais longa, totalizando nove meses consecutivos. Esses períodos permitiram que o meu trabalho pudesse ter sido escutado e ao mesmo tempo interferido pelo diálogo aberto e instigante com colegas e alunos da pós-graduação em educação. Ministrei vários cursos, organizei e participei em seminários, proferi palestras e conferências, além de ter tido a honra e a grata experiência de fazer comunicações conjuntas e redigir textos em conjunto. Verdadeiramente posso dizer que me foi dada a oportunidade, em São Paulo, de ensaiar e intensificar formas de trabalho experimental, de aprofundar ou produzir novas modalidades do estar-junto, de viver o que Roland Barthes definiu como uma relação em estrela.

As minhas primeiras intervenções continuaram o trabalho desenvolvido na tese e versaram a questão maior da transformação da criança em aluno na nossa civilização, dirigindose para a configuração da intimidade infantojuvenil em ambiente escolar, bem como para as tecnologias de governo da alma na modernidade, em associação estreita com o higienismo, a médico-pedagogia e a psicopedagogia da primeira metade do século passado. Neste contexto, tive a oportunidade de coorientar, com Denice Catani e ainda no âmbito das áreas da História da Educação e da Educação Comparada, duas teses de doutoramento - de Constantina Xavier Filha e de Renata Marcílio Cândido - e de supervisionar o doutoramento sanduiche de José Roberto Gomes Rodrigues. Como resultado dos estudos que fui desenvolvendo no âmbito da comparação dos sistemas educativos dos países de língua portuguesa pude ainda publicar, em 2009, juntamente com o meu colega Luís Miguel Carvalho - e atualmente meu diretor no Instituto de Educação da Universidade de Lisboa -, a monografia A circulação do Conhecimento Pedagógico e a Invenção da Criança Problema: Estudos Comparados Portugal-Brasil (1880-1960).

Por essa altura iniciava já com Júlio Groppa uma ativa e construtiva parceria que viria a prolongar e a redirecionar o conjunto das reflexões e estudos que havia feito em torno de Michel Foucault. Daqui lhe envio também o meu mais sentido e vivo agradecimento. Ambos conduzimos um projeto de investigação, apoiado pelo CNPq, a que demos o nome de Foucault e a escrita, no interior do qual tivemos a oportunidade de produzir um levantamento exaustivo - tanto nas monografias quanto nos Dits et Ecrits - das referências do pensador francês concernentes aos problemas do exercício da produção, circulação e rarefação do discurso nas sociedades modernas e contemporâneas. No decurso destas atividades, Júlio Groppa viria a até ao Instituto de Educação da Universidade de Lisboa como professor visitante, no segundo semestre de 2010, e, no ano seguinte, eu mesmo teria, como já afirmei, a oportunidade de a seu convite passar a mais longa temporada em São Paulo. Foi uma experiência a todos os títulos 
$(\infty c)$ EY

enriquecedora. Estiveram igualmente envolvidos nestas atividades oito alunos de doutoramento comuns. Pude, além disso, também supervisionar o pós-doutoramento de Fábio Zanoni e os doutoramentos sanduiche de Daniele Kowalewski, Gisela Maria do Val e Elisa Vieira, provenientes da FE-USP.

Foi ainda em São Paulo que a minha investigação viria a sofrer um importante deslocamento em cuja trajetória ainda permaneço e permanecerei, sem dúvida. Os problemas relacionados com o ato da criação escrita e o que possa ser uma pedagogia do seminário por vir passaram a ocupar o centro das minhas preocupações e estão espelhadas longamente no meu último livro dado à estampa em 2019 a que dei o título Fazer a mão: Por uma escrita inventiva na universidade. Na FE-USP pude começar a pensar alto sobre possíveis desenvolvimentos teóricos e também na minha própria experiência de docente, sobretudo como orientador de dissertações e teses. Uma pergunta passou a assomar ao meu espírito e com ela tenho convivido. O que pode um professor? É exatamente com ela que se inicia este meu livro. Sobretudo na interação com os estudantes da pós-graduação, aprendi a reconhecer-me num plano, de resto sempre instável, em que a minha posição afeta e se reconhece afetada pela relação estabelecida entre as inteligências, as palavras e os enunciados que transitam no interior de uma sala de aula. Nas estadias na Faculdade de Educação foi-se tornando cada vez mais nítida e necessária para mim a produção de um jogo de autoanálise e autorreflexão, e é daí que derivam as minhas atuais preocupações em torno da pedagogia do ensino superior. Para mim, trata-se de tomar posse de uma profissão, a de universitário, na qual se entra a partir do mérito científico, mas para a qual ninguém foi efetivamente preparado. Sendo assim, é natural que o lugar de docente nos ocupe a nós universitários ao invés de nós o ocuparmos; e daí, a meu ver, também, a manutenção e reprodução inquestionada de tantas práticas de ensino e de trabalho anacrónicas e sem o menor sentido, já ontem como hoje, tanto desânimo entre estudantes face à ausência de rotinas que levem ao domínio dos métodos e processos por meio dos quais a potência da criação se expande.

Tudo me conduzia até a uma reflexão sobre a experiência e o espaço em que me encontrava. E assim também eu passei a estudar e a tentar escrever sobre aquela grande astúcia da universidade a que, desde o princípio do século XIX e a partir da Alemanha, se veio a dar o nome de seminário de investigação. Trata-se a bem dizer de um dispositivo relacional tão simples de conceber e fazer acontecer, tão insistentemente invocado, mas na realidade tão difícil de erguer em instituições académicas, como as de tradição francófona, que é o caso da universidade portuguesa, em que ainda hoje predomina a dimensão ensinante e a transmissão de conteúdos já feitos, mesmo na pós-graduação. 
Tentei aos poucos e a partir das minhas vivências na FE-USP - onde ministrei cursos muito concentrados de 30 e mais horas por vezes numa ou duas semanas - organizar uma modalidade próxima do que idealizava fosse verdadeiramente um seminário e mantivesse essência dialógica que nele está suposta desde a origem. Comecei em São Paulo a entregar-me a uma experiência repetitiva em absoluto entusiasmante. Eis em traços muito grosseiros a imagem do que procurei fazer: um grupo de estudantes organiza-se à volta de uma mesa e sobre a qual se encontra um mesmo texto, previamente lido e trabalhado individualmente, mas que, nessa situação, se torna novamente objeto de conversa, de discussão e análise, como se existissem múltiplas possibilidades de o abordar; um artigo, um capítulo ou uma parte de uma obra estão ali para serem ativamente explorados e quase dissecados, a fim de promover e suscitar níveis de compreensão e apreensão tão diversos quanto o número de participantes que se encontravam envolvidos. Para mim foi como se, nesta situação tão concreta e tornada banal através do processo da sua repetição, se pudesse consumar afinal um grande e velho princípio existencial, ético e político da cultura ocidental: que é pela constante articulação da palavra oral com a palavra escrita que todos estamos a ser convidados, e nos convidamos de facto, a fazer parte do movimento de produção do discurso e da construção do sentido. Não apenas a viver, mas a participar na composição da vida, trabalhando com afinco nessa elipse que nos conduziria ao desconhecido a partir de necessidades e problemas que se originavam no interior de nós mesmos. Um exercício de pura singularização.

Como se o investigar pudesse corresponder a uma autêntica arte de existir, tão diversa daquela que encontrara nas fontes documentais que compulsara e analisara no doutoramento. Ora, o trabalhar para afirmar estoutra possibilidade, nos dias que passam, faz-nos sentir continuadores de uma notável tradição intelectual que remonta às escolas de Platão e de Aristóteles, aquelas em que um mesmo problema teórico se discutia num determinado dia e poderia ser retomado noutros termos mais tarde, dando origem também a diferentes problemáticas e produções escritas. Então, é da circulação irrestrita e ininterrupta da palavra que se trata afinal num seminário de investigação; e quem ousar entregar-se a esta tarefa tem de compreender muito bem que não está só e que é precedido por muitos e variados colegas. Há atrás de nós um brilho e uma coragem em defesa de uma universidade da criação, um combate intenso contra a lógica do mesmo que em conjunto procurávamos reatar nos nossos encontros. Nada de mais exaltante do que participar nesta aventura espiritual em que nos sentimos ligados a uma tradição e ao porvir de um gesto.

Diria assim, de novo, como princípio geral da natureza do trabalho académico com que me identifico e cujo treino, repito, iniciei na FE-USP: um grupo de sujeitos que se encontra a 
uma hora estipulada, que conversa, longa e detalhadamente, a fim de descobrir as mil e uma entradas de um texto que está sobre a mesa; um grupo em que todos os seus integrantes estão focados em isolar e tomar posse de elementos metodológicos de construção do texto e a pensar como existem trechos, linhas, ideias que comunicam diretamente com o seu objeto de pesquisa; um grupo em que a análise e a interpretação afirmam continuadamente o princípio de que um enunciado, seja ele de que tipo for, espelha sempre uma filiação múltipla, uma presença intertextual. Compreendem em conjunto que o ofício de investigador se constrói a partir da referenciação. É na posse dessa certeza mesma que cada um irá descobrindo e construindo as passagens ao seu próprio texto. Aprende-se assim que a universidade nos devolve o tempo da espera, nos permite um investimento na arte da intersecção dos enunciados.

Para os participantes deste tipo de seminário importa, a cada sessão, que o objeto de pesquisa possa ser mais pensado, mais elaborado, mais vivificado, que o lugar do investigadorescritor encontre condições de se ir exercendo, dando assim corpo a uma cultura científica que já não confunde minimamente rigor e labor desmedido com normalização do pensamento. Todos conduzem e são conduzidos no seminário, e dessa forma o trabalho sobre um texto situase muito além da fixação de uma interpretação legítima e uniforme; ao contrário, o diálogo e a troca de ideias ou de pontos de vista, mesmo se sempre feitos a partir de uma leitura conjunta, consubstanciam uma metodologia da individualização no acesso ao conhecimento: cada um toma as suas próprias notas, ora sobre uma parcela do discurso lido, ora sobre um passo da conversa, que o capturava num instante qualquer; cada um intervém para o coletivo, inclusive com o seu silêncio; cada um passa a saber que precisa do olhar e da escuta atenta dos colegas e do condutor da sessão para se entender um pouco melhor com as suas próprias palavras, para se habituar a esse patamar da compreensão que consiste em tornar um pensamento mais percetível no interior do fluxo do seu próprio estar a acontecer.

O seminário passa assim a constituir um lugar comunitário de grande exigência, aquela que autoriza um aluno, e também um professor experimentado, a tomar posse da pertinência do seu objeto particular de pesquisa no contacto com outros textos e interpretações. Trata-se, portanto, de uma pedagogia em que o ler, o falar e o anotar se colocam completamente ao serviço de uma prática de contacto com a produção escrita que há de, ela mesma, vir a concretizar-se e a exprimir-se um dia, também ali, no próprio espaço do seminário, como escrita e conhecimento novo subscrito por um dos seus membros. Todos os participantes estão da mesma maneira envolvidos e são regularmente obrigados a expor os seus trabalhos em andamento ao grupo, a ocupar a posição do investigador. 
É dessa forma que, enquanto decorre o seminário, cada participante se vai apercebendo de si enquanto ser-na-linguagem. Creio acompanhar Giorgio Agamben quando este, em $A$ potência do pensamento, se refere à nossa como sendo a época em que a herança niilista se transformou numa autêntica "revolução coperniciana", justamente aquela em que o homem se vem descobrindo "lançado na linguagem, sem ter uma voz ou uma palavra divina que lhe garantam a possibilidade de escapar ao jogo infinito das proposições significantes”. É essa a evidência de que nunca nos podemos esquecer, sempre que a voz da verdade e da instituição nos circundarem ou mesmo nos assaltarem; e também aquela a que havemos de recorrer quando retornar em nós o mecanismo escolar da impotência, esse não estar a ser capaz de avançar. Somos aqueles para quem a linguagem foi perdendo todos os véus - da teologia, da ontologia, da psicologia, da pedagogia... - e que aceitam encontrar-se a sós com ela, que se podem acercar dos seus limites e com cujo trabalho crítico procuram transpor os interditos e tentam expulsar o indizível. Nestes termos falo do seminário universitário como uma comunidade "não pressuposta", que não expõe ideias sobre a linguagem, mas cujos membros se expõem a si mesmos a partir de uma certa ideia da linguagem. Forma-se aí um coletivo cuja revelação e possibilidade existencial não consistem numa fatalidade, mas em mostrar "que toda a palavra e todo o conhecimento humano têm a sua raiz e o seu fundamento numa abertura que os transcende infinitamente", residindo nessa abertura prévia da linguagem a possibilidade de cada um afirmar e fazer existir o seu trabalho escritural (Agamben, 2013: 27 e 32). Tive a subida felicidade de ver este ano de 2021 publicado na Revista Educação e Pesquisa um artigo meu em que estas questões da pedagogia do seminário, que aqui trato de forma apressada, se encontram mais desenvolvidas.

Estar em diálogo com os outros, ter um contrato com eles para se acercar da interioridade do seu próprio pensamento constitui a manifestação mais elevada do ser-em-comum. Intensidade da escuta e um estado de pura exposição de um rosto com outros rostos. O ser-emcomum implica, sempre, um ter-lugar, um participar da grande exigência comunitária, a exigência da reciprocidade. Esta, no seminário, dá conta não de uma sociedade perfeita, mas de uma humanidade transparente, em que o dizer se sobrepõe ao dito, em que a existência de cada ser convoca e chama a do outro, ou uma pluralidade de outros, a uma efervescência e à imbricação de motivações dissemelhantes. Uma comunidade que está em comunhão, mas não cessa de produzir dissensos. Todos têm palavras a ser proferidas - é preciso fazer a fala acontecer! - e é nesse sentido concreto que me parece ter Blanchot assimilado, desta feita em A comunidade inconfessável, a exigência da comunidade ao comunismo, tomando ambos os conceitos como sintomas e sinais históricos da imanência absoluta do homem ao homem. Neste 
(cc) EY

seu livro, Blanchot não cessou de convocar o escritor Georges Bataille, para quem só a comunidade possuía a faculdade de fazer acordar essa consciência de incompletude e insuficiência que atravessa cada um de nós. E Blanchot retirou do autor de A experiência interior estas afirmações: “'a substância de cada ser é contestada por cada outro sem repouso'/'mesmo o olhar que exprime o amor e a admiração se liga a mim como uma dúvida que toca a realidade'/'o que eu penso, eu não o pensei sozinho"' (Bataille citado por Blanchot, 2013: 17). Uma vez isolado, o ser está fechado, adormecido e por isso impossibilitado de desdobrar o pensamento. Não me esqueço que foi num dos passeios com Denice Catani no bairro de Higienópolis, talvez em 2001 que, pela sua mão tive pela primeira vez contato com a obra de Blanchot, a qual que viria a produzir em mim um efeito incrível, tendo-se tornado um interlocutor privilegiado no meu trabalho desde então.

$\mathrm{Na}$ relação pedagógica passei a experimentar o postulado segundo o qual o conhecimento não se encontra amestrado nem é amestrável, tendo o seminário passado a representar para mim o setting de uma aprendizagem escolar que não reconhece qualquer soberania, seja a da razão, a do sujeito ou da palavra última e verdadeira do texto em apreço.

Tal evidência conduzir-me-ia, ao mesmo tempo e em simultâneo com o aprofundamento das leituras que vinha fazendo dos escritos de Michel Foucault, ao coração da experiência filosófica do chamado pós-estruturalismo e que se expandiu a partir do início nos anos 60 do século passado. Na realidade, foi aí que se veio a sedimentar uma intensa reflexão dirigida aos fundamentos e limites do conhecimento. Os cursos e seminários que organizei em São Paulo permitiram que visitasse, com grande vagar, a produção crítica de autores como Roland Barthes, Gilles Deleuze, Maurice Blanchot, Jacques Derrida, Michel de Certeau ou Julia Kristeva. Com eles pudemos perceber como os processos escriturais podem passar a ser discutidos enquanto prática indefinidamente recomeçada de diferenças, como um jogo intertextual. Neles, essa posição trazia implicado que a reflexão acerca da criação se dirigisse para os procedimentos da sua própria organização, para os planos de imanência, as fronteiras e os limiares do discurso. Na verdade, percorreu esta geração de investigadores - que soube sempre como encontrar forma de interpenetrar temas e problemas advindos da filosofia, da literatura, da arte, do cinema, da psicologia, da etnologia, da história... - uma mesma compreensão teórica da produção textual, razão pela qual os elementos linguísticos e simbólicos começaram a ser tomados a partir das respetivas inter-relações e não mais isoladamente ou numa situação de dependência sistémica. Nessa medida, o pós-estruturalismo não se limitou a defender o caráter incerto, indeterminado e instável de qualquer discurso, mas, para fazer explodir as teses então absolutamente prevalecentes da linearidade do enunciado - das estruturas fixas e rígidas de significação, de 
$(\mathrm{cc}) \mathrm{EY}$

um conhecimento produzido por um eu racional, autotransparente, capaz de fornecer verdades objetivas e universais sobre o mundo -, dirigiu-se amiúde aos fundamentos da linguagem, questionando e pondo a nu os códigos e as regras de construção da narrativa, seja esta de que natureza for. Nas suas múltiplas abordagens, estes autores tomaram o ato de criação como correspondendo ao trabalho de assimilação, de transformação e de deslocamento do pensar e do escrever, numa posição epistemológica profundamente antirrealista, ou seja, que se recusou a ver o conhecimento como uma representação precisa da realidade.

E, talvez para surpresa de muitos de nós, vários deles tiveram ainda necessidade - eu diria que igualmente vital para os respetivos projetos intelectuais e académicos - de atrelarem também a essas suas teorizações sobre o ser da linguagem um pensamento organizado acerca do gesto de ensinar e de aprender. Centraram-se, não raro, em defender a necessidade de uma educação permanente, capaz de rever os seus pressupostos sobre que assenta a construção e a circulação do saber e do espaço da sala de aula e do seminário como um estar a ser junto. Como se houvesse ainda nas figuras de Deleuze, Barthes, Derrida ou mais recentemente de Rancière um pedagogo em andamento, que recusa com a maior verticalidade ética vestir a pele do transmissor, do divulgador, do mero comentador da obra alheia. De cada vez que se nos dirigem nessa condição de professores-investigadores é invariavelmente para nos mostrar, através do seu exemplo e testemunho, como esse ofício ou como essa posição pode ser ocupada a partir de uma ideia preparada e refletida, mas que está sempre a recomeçar ali mesmo no espaço da sala de aula, uma pesquisa que se desenvolve como um vento forte: que nos pode mostrar a adjunção, o desmembramento ou até mesmo a desagregação de uma ideia, de um conceito, de uma paisagem empírica, mas que não se faz compreender imediatamente, deixando-nos impactados bem para lá do momento da sua passagem. Seja de que ângulo for, com eles deparamo-nos sempre com uma prática da interrogação que atinge não apenas a matriz da palavra, quanto a sua organização, mutação e até comunicação pública.

Ora, tudo o que obrigue a rever radicalmente as conceções universais que incorporámos, e que se tornaram perduráveis, acerca da natureza do trabalho que fazemos enquanto investigadores e professores aprendizes só nos pode beneficiar e fazer crescer. A operação crítica que esta geração dos anos 60 do século passado concretizou continua a cativar-me, porque jamais abandonou a sua posição de princípio: a de que o conhecimento e o saber se renovam e afirmam performaticamente, ora tanto a partir de uma prática da desmontagem e do desmantelamento dos sistemas de estabilização da significação, que se vão gerando no seu próprio interior, ora admitindo que as noções de confluência, colagem, ambivalência, hibridização, e não as de unidade ou totalidade, são as que mais e melhor definem a natureza 
de um enunciado. Com eles somos conduzidos ao coração do texto, às figuras do seu produtor e leitor, a um tipo de experiência da heterogeneidade que supõe que o método se vá construindo a si mesmo, porque não tem atrás de si nenhum privilégio epistemológico fundacional, a estabilidade de qualquer sistema de pensamento ou modelo textual; tão apenas imbricação, textura e trama.

Nas longas e tranquilas tardes e noites que passei na FE-USP ou deambulando pela cidade, nas trocas de palavras com alunos e colegas pude acercar-me do que para mim constitui essencial da nossa arte pedagógica e escritural - que a obra em andamento e o andamento da obra está sempre a convocar o pensar da própria obra. É por aí - ainda e uma outra vez - que mais nos aproximamos de um entendimento alargado e aberto da noção de texto, daquela postura de que estamos sempre carentes para dar curso ao desejo de escrita que transportamos em nós mesmos. A nossa fome de compreensão dos mecanismos de composição textual, dos instrumentos que permitam a sua reinvenção, assim como das armadilhas que se apresentam ao caminhar, não se extingue e está sempre necessitada de novas precauções, de novos aditamentos. Foi para aí que, em São Paulo, aprendi a dirigir-me; é a essa herança que testemunho aqui a minha fidelidade. Muito obrigado.

Lisboa, 15 de Dezembro de 2021

\section{REFERÊNCIAS}

AGAMBEN, G. A potência do pensamento. Lisboa: Gradiva. 2013.

BLANCHOT, M. A comunidade inconfessável. Brasília: Editora Universidade de Brasília, 2013.

NÓVOA, António; CARVALHO, Luís Miguel; CORREIA, António Carlos; MADEIRA, Ana Isabel Madeira \& Ó, Jorge Ramos do. Educational Knowledge and its Circulation: Historical and Comparative Approaches of Portuguese-Speaking Countries. Lisboa: Educa/Prestige, 2013b. Disponível em: http://hdl.handle.net/10451/7409.

Ó, Jorge Ramos do. Pedagogia do seminário universitário: proveniência histórica e tradução contemporânea. Educação e Pesquisa, 47, 1-21, 2021.

Ó, Jorge Ramos do. Fazer a mão: por uma escrita inventiva na universidade. Lisboa: Edições do Saguão, 2019.

Ó, Jorge Ramos do; Aquino, Julio Groppa. Teaching as courage of truth: Pedagogy and Parrehsia. In Miguel A. Pereyra \& Barry M. Franklin (Eds.). Systems of reason and the politics of schooling: School reform and sciences of education in the tradition of Thomas $\mathrm{S}$. Popkewitz. New York: Routledge, 2014a. pp. 336-349. 
Ó, Jorge Ramos do \& Aquino, Julio Groppa (2014b). Em direção a uma nova ética do existir: Foucault e a experiência da escrita. Educação e Filosofia, 28 (55), 199-23. Disponível em: https://doi.org/10.14393/REVEDFIL.

Ó, Jorge Ramos do \& Carvalho, Luís. A circulação do Conhecimento Pedagógico e a Invenção da Criança Problema: Estudos Comparados Portugal-Brasil (1880-1960). Lisboa: Educa \& Ui\&dCE, 2009.

Ó, Jorge Ramos do (2003a). O Governo de Si Mesmo: Modernidade pedagógica e encenações disciplinares do aluno liceal (último quartel do século XIX-meados do século XX). Lisboa: Educa, 2003a.

Recebido em: 11 novembro de 2021

Aceito em: 26 de dezembro de 2021 